\title{
Central Nervous System Mature Teratoma
}

National Cancer Institute

\section{Source}

National Cancer Institute. Central Nervous System Mature Teratoma. NCI Thesaurus.

Code C7013.

A mature teratoma arising in the central nervous system. 